\title{
Reduced activity of Adenylyl Cyclase 1 Attenuates Morphine Induced Hyperalgesia and Inflammatory Pain in Mice.
}

\author{
Kayla Johnson $^{1}$, Alexis Doucette ${ }^{1}$, Alexis Edwards ${ }^{1}$, Val J. Watts ${ }^{2}$, Amanda H. Klein ${ }^{1}$ \\ ${ }^{1}$ Department of Pharmacy Practice and Pharmaceutical Sciences, University of Minnesota, \\ Duluth, MN \\ ${ }^{2}$ Medicinal Chemistry and Molecular Pharmacology, Purdue University, West Lafayette, IN
}

\begin{abstract}
Opioid tolerance and opioid-induced hyperalgesia during repeated opioid administration and chronic pain are associated with upregulation of adenylyl cyclase activity. The objective of this study was to test the hypothesis that a reduction in adenylyl cyclase 1 (AC1) activity or expression would attenuate morphine tolerance and hypersensitivity, and inflammatory pain using murine models. To investigate opioid tolerance and opioid-induced hyperalgesia, mice were subjected to twice daily treatments of saline or morphine using either a static $(15 \mathrm{mg} / \mathrm{kg}, 5$ days) or an escalating tolerance paradigm (10-40 mg/kg, 4 days). Systemic treatment with an AC1 inhibitor, ST03437 (5 mg/kg, ip), reduced morphine tolerance and morphine hyperalgesia in mice. Lumbar intrathecal administration of a vector incorporating adeno-associated virus and short-hairpin RNA against Adcy1 reduced morphine induced hypersensitivity compared to control vector treated mice. In contrast, morphine antinociception, along with baseline thermal paw withdrawal latencies, motor performance, exploration in an open field test, and burrowing behaviors were not affected by intrathecal Adcy1 knockdown. Knockdown of Adcy1 by intrathecal injection also attenuated inflammatory mechanical hyperalgesia after intraplantar administration of Complete Freund's Adjuvant (CFA) after one week post injection. This Adcy1 knockdown strategy also increased burrowing and nesting activity after CFA injection when compared to controls. Together, these data indicate targeting AC1 to mitigate opioid-induced adverse effects, or as a method to treat chronic pain, are appropriate as a clinical approach and further development into generating pharmaceuticals targeting these genes/proteins may prove beneficial in the future.
\end{abstract}

\section{Introduction}

Opioids are one of the most common analgesics used to alleviate pain clinically by inhibiting neuronal signal transmission through the mu opioid receptor (MOR). Individuals with chronic pain use opioids on a daily basis for pain management, causing the development of analgesic tolerance, leading to dosage escalation. In the clinic, tolerance is defined as a requirement for increased opioid doses to maintain analgesia. Opioid-induced hypersensitivity is defined as the increased sensitivity to pain as a result of chronic opioid use. Whether the increased opioid requirement is caused by the decreasing analgesic efficacy of the drug, as in tolerance, or by an increase in spontaneous pain or lowering the nociceptive threshold, the clinical effect is the same [19]. Furthermore, if the patient ceases therapy, there is a possibility for withdrawal and nerve hypersensitivity, increasing the likelihood for opioid dependence and abuse situations. 
Upon agonist binding to the MOR, adenylyl cyclase (AC) is inhibited thereby blocking the formation of cyclic adenosine monophosphate (cAMP). However, prolonged agonist stimulation of the MOR leads to an inability to inhibit AC, or a phenomenon called heterologous sensitization of AC, causing intracellular activity of AC to increase, thereby increasing intracellular levels of cAMP [43]. Enhancement of cAMP levels due to prolonged opioid exposure has long been connected to opioid tolerance and opioid dependence in both in vitro [7; 33] and in vivo studies, particularly in the spinal cord and dorsal root ganglia (DRG)[9; 29]. More recently, the activation of $\mathrm{Ca}^{2+} /$ calmodulin ACs, particularly AC1 and AC8, were implicated in the initial stages of morphine tolerance and withdrawal as AC1 and AC8 knockout mice have increased latencies during the first few days of morphine tolerance testing as well as decreased withdrawal behaviors [25; 47]. AC1 and AC8 have also been linked to the development of both acute and chronic persistent inflammatory pain [16; 17; 36; 42] and a global loss of either AC1 or AC8, or in combination, appear to have a role in attenuating morphine tolerance and withdrawal [37; 40]. However in an inflammatory pain model in mice, loss of AC1, but not AC8, decreased nocifensive responses to formalin[36]. AC isoform-selective pharmacological inhibitors have been developed, particularly for AC1, and appear to attenuate chronic pain in mice $[4 ; 21 ; 26 ; 39]$. Of note ST034307, a highly selective inhibitor for AC1, has shown effectiveness at providing analgesia in a mouse model of inflammatory pain [4]. To date, it is unknown if selectively inhibiting AC1 activity or reducing AC1 expression after chronic MOR stimulation alters the development of opioid tolerance and opioid-induced hypersensitivity.

The purpose of this study was to better understand the activity of AC1 during morphine tolerance, opioid induced hypersensitivity and chronic inflammatory pain. To accomplish this, pharmacological inhibition of AC1 or a short hairpin RNA (shRNA) knockdown strategy using adeno associated virus (AAV9) vector was used to decrease activity/expression of Adcy1. Systemic treatment with ST03437, reduced morphine tolerance and morphine hyperalgesia in mice. Similarly, behavioral measures indicate intrathecal administration of a viral vector expressing Adcy1 shRNA in mice attenuates morphine tolerance, opioid-induced hypersensitivity, and decreases evoked pain measures in a mouse model of inflammatory pain.

\section{Materials and Methods}

\section{Animals}

All experimental procedures involving animals were approved and performed in accordance with the University of Minnesota Institutional Animal Care and Use Committee guidelines. Adult male C57Bl6 mice were obtained via Charles River (5-6 weeks old, Raleigh, NC). Mice were acclimated to individual testing apparatuses prior to behavioral testing. Mice were euthanized by isoflurane anesthesia (5\%) followed by decapitation at the end of the study.

\section{Tissue Collection and mRNA Isolation}

Tissues harvested from animals were flash frozen in liquid nitrogen and stored at $-80{ }^{\circ} \mathrm{C}$. Total mRNA was isolated from tissues using Tri Reagent (T9424, Sigma Aldrich, St. Louis, MO) and RNeasy Mini Kit (Qiagen, Germantown, MD) according to manufacturer’s protocol with DNase 
digestion. Complimentary DNA synthesis was performed with 50 ng total mRNA using Omniscript RT Kit (Qiagen, Germantown, MD) and random nonamers (Integrated DNA Technologies, Coralville, Iowa) according to manufacturer's protocol.

\section{Quantitative PCR}

Quantitative PCR was performed using SYBR Green I dye with LightCycler 480 technology (Roche, Branchburg, NJ, USA). The cDNA copy number was typically quantified against a $\geq 5$ point, 10-fold serial dilution of a gene specific cDNA standard. Internal controls included negative RT-PCR samples and comparative expression versus a housekeeping gene, $18 S$. Fold expression of each gene of interest was determined by: (mean gene concentration/mean 18s concentration)/(mean gene concentration in saline/mean 18s concentration in saline). See Supplemental Table 1 for gene specific primers used.

\section{Drugs and Delivery}

Morphine (Sigma Chemical, St. Louis, MO) was administered through a $100 \mathrm{uL}$ subcutaneous injection in saline. ST034307 (6271, Tocris Bioscience, Minneapolis, MN) was dissolved in 10\% $\beta$-cyclodextrin with 5\% DMSO in saline and administered $5 \mathrm{mg} / \mathrm{kg}$ through a $100 \mathrm{uL}$ intraperitoneal injection 15 minutes after morphine administration. Morphine efficacy was determined using an escalating dose response curve $(5-20 \mathrm{mg} / \mathrm{kg})$ waiting 30 minutes after each injection [22]. For morphine tolerance experiments, baseline mechanical paw withdrawal testing was performed before administration of $15 \mathrm{mg} / \mathrm{kg}$ morphine for five days [27]. Escalating morphine tolerance was performed similarly, except increasing doses of morphine, starting at 10 $\mathrm{mg} / \mathrm{kg}$ and increasing $10 \mathrm{mg} / \mathrm{kg} / \mathrm{day}$, were administered over the course of four days. In each model, morphine was delivered twice per day ( 0800 and 1800 hours). Mechanical threshold testing was performed 30 and 60 minutes post morphine administration in the morning. To determine the degree of opioid-induced hyperalgesia, paw withdrawal thresholds were assessed starting 18 hours after the last dose of morphine. Complete Freund's Adjuvant (CFA, F5881, Sigma Chemical, St. Louis, MO) was administered through an intraplantar injection (20 uL, undiluted) into the left hind paw. [23; 24].

\section{Mechanical Paw Withdrawal}

Mice were acclimated to testing environment on at least two separate occasion for 30 to 60 minutes before formal testing. Testing environment consisted of a mesh floor, allowing access to animal hind paws, and individual clear acrylic chambers. Mechanical paw withdrawal (MPW) thresholds were determined by use of electronic von Frey testing equipment (Electric von Frey Anesthesiometer, 2390, Almemo ${ }^{\circledR}$ 2450, IITC Life Science, Woodland Hills, CA). The plantar surface of the hind paws were gently pressed with the probe until a nocifensive response (i.e. paw lifting, jumping, and licking) was elicted. Baseline measurements (in grams) were collected five times from both the right and left hind paw and averaged, with an interstimulus interval of at least one minute.

\section{Thermal Paw Withdrawal}


Testing environment consisted of a glass floor heated to $30^{\circ} \mathrm{C}$ with individual clear acrylic chambers. The modified Hargreaves method was used to measure thermal paw withdrawal (TPW) latency (Plantar Test Analgesia Meter, 400, IITC, Woodland Hills, CA) [5]. TPW latencies were determined by the amount of time (in seconds) a heat radiant beam of light focused on the plantar surface of the hind paw was required to elicit a nocifensive response (e.g. paw lifting, shaking, and licking). A maximum time limit of 20 seconds exposure to the beam was used to avoid tissue damage. Baseline measurements were collected five times from both the right and left hind paw and averaged, with an interstimulus interval of at least two minutes.

\section{Adeno-Associated Virus Serotype 9 (AAV9)-Mediated Adcy1 Knockdown}

Gene knockdown of Adcy1 using shRNA was achieved using AAV9-GFP-U6-m-Adcy1-shRNA with AAV9-GFP-U6-scramble-shRNA as control viral vector (shAAV-251792 and 7045, titer: $1.4 \times 10^{13} \mathrm{GC} / \mathrm{mL}$, in PBS with 5\% glycerol, Vector Biolabs, Malvern, PA, United States). Vectors were delivered by direct lumbar puncture $(10 \mathrm{uL})$ in awake mice and behavioral assessments were performed 4-8 weeks post injection [13; 38].

Rotarod Performance Test

Agility assessment was conducted using Rotamex-5 automated rotarod system (0254-2002L, $3 \mathrm{~cm}$ rod, Columbus Instruments, Columbus, $\mathrm{OH}$ ). Mice were placed onto a stationary knurled PCV rod suspended in the air. The initial rotation speed of $4 \mathrm{rpm}$ was gradually increased by 1 rpm in 30-second intervals until animals fell off the rod or reached a speed of $14 \mathrm{rpm}$ (300 seconds). Two tests were administered per animal and averaged.

\section{Burrowing Testing}

Mice were acclimated to empty burrowing tubes for $\sim 2$ hours on at least two separate occasions before formal testing. The burrows were made from a $6 \mathrm{~cm}$ diameter plastic pipe and $5 \mathrm{~cm}$ machine screws were used to elevate the open end by $3 \mathrm{~cm}$ [11]. During testing, each mouse was placed in an individual cage with a burrowing tube containing $500 \mathrm{~g}$ of pea gravel. The amount of gravel remaining in the tube after 2 hours was used to calculate the total percent of gravel displaced from the burrow.

\section{Open Field Testing}

The open field testing arena consisted of a 40 x $40 \mathrm{~cm}$ box with a white floor and black walls. Animals were placed in the open field arena, in a room with controlled adjustable lighting, and baseline activity was recorded for 30 minutes (Sony Handycam, HDR-CX405, Sony Corp., Tokyo, Japan). The distance traveled, time spent immobile, average velocity, and the change in orientation angle were computed by using data output from the Ethowatcher computational tool software (Laboratory of Bioengineering of the Institute of Biomedical Engineering and the Laboratory of Comparative Neurophysiology of the Federal University of Santa Catarina, UFSC, available: http://ethowatcher.paginas.ufsc.br/) [10].

\section{Nesting}


Mice were individually housed in clean plastic cages containing cob bedding with food and water ad libitum overnight. A single 2" Nestlets ${ }^{\mathrm{TM}}$ (Ancare Corp., Bellmore, NY) square was weighed and added to each cage. The next morning ( 14 hours) untorn pieces of each nesting square were weighed and the resulting nests were photographed and scored on a 5-point scale as described previously [11]. Briefly the scoring system was: $1=>90 \%$ intact, $2=$ partially torn, 3 $=$ mostly shredded but no identifiable nest, $4=>90 \%$ torn but flat nest site, $5=>90 \%$ torn with resulting crater nest. Scores with 0.5 units were used for nests with scores in between the aforementioned intervals.

\section{Microscopy}

Histological sections were taken in spinal cord, DRG and sciatic nerves in order to verify the delivery of the AAV9 vector within the lumbar intrathecal space. Verification of virus inoculation were visible by the presence of green fluorescent protein (GFP). Sections (10 uM, Leica CM3050) were mounted onto electrostatically charged slides and images were collected using a Nikon TiS Microscope and associated software.

\section{C-fiber Compound Action Potentials}

Compound action potentials (CAPs) were measured from both left and right desheathed sciatic nerves from AAV9-GFP-U6-m-Adcy1-shRNA and AAV9-GFP-U6-scramble-shRNA 8 weeks after intrathecal injection. Sciatic nerves were dissected from the hind limbs of mice and recordings were performed the day of harvesting. Each nerve was mounted in a chamber filled with superficial interstitial fluid composed of $107.7 \mathrm{mM} \mathrm{NaCl}, 3.5 \mathrm{mM} \mathrm{KCl,} 0.69 \mathrm{mM} \mathrm{MgSO}_{4}$, $26.2 \mathrm{mM} \mathrm{NaCO}_{3}, 1.67 \mathrm{mM} \mathrm{NaH}_{2} \mathrm{PO}_{4}, 1.5 \mathrm{mM} \mathrm{CaCl}_{2}$, $9.64 \mathrm{mM} \mathrm{Na}^{+}$gluconate, $5.5 \mathrm{mM}$ dglucose, and $7.6 \mathrm{mM}$ sucrose, $\mathrm{pH} 7.4$ (bubbled with $95 \% \mathrm{O}_{2}, 5 \% \mathrm{CO}_{2}$ ). Electrical stimulation was performed at a frequency of $0.3 \mathrm{~Hz}$ with electric pulses of 100- $\mu$ s duration at 100-10,000 uA delivered by a pulse stimulator (2100, AM Systems, Carlsborg, WA). Evoked CAPs were recorded with electrodes placed $\sim 5 \mathrm{~mm}$ from the stimulating electrodes. Dapsys software was used for data capture and analysis (Brian Turnquist, Bethel University, St. Paul, MN, $w w w$.dapsys.net). The stimulus with the lowest voltage producing a detectable response in the nerve was determined the threshold stimulus. The stimulus voltage where the amplitude of the response no longer increased was determined to be the peak amplitude. The conduction velocity was calculated by dividing the latency period, the time from stimulus application to neuronal initial response, by the stimulus-to-recording electrode distance.

\section{Data analysis}

Data were collected by personnel blinded to the animal condition and treatment. The appropriate t-test, one-way, two-way, or repeated measures ANOVA followed by Bonferroni's post hoc analysis was used to determine significance for MPW thresholds and TPW latencies, gene expression, burrowing, open field testing, rotarod assessments, and CAP recordings.

Nonparametric tests were used for nesting behaviors. All statistical analyses were carried out using GraphPad Prism versions 7.0 and 8.0 (GraphPad Software, San Diego, CA). All other data is presented as mean \pm SEM with $\mathrm{p}<0.05$ considered statistically significant. 


\section{Results}

Adcy1 mRNA expression is increased in in the peripheral nervous system and spinal cord in mice after chronic administration of morphine

Chronic exposure of the MOR to agonists causes a decreased inhibitory response by the MOR and increases the adenylyl cyclase/cyclic-AMP activity[44]. We attempted to confirm these findings by analyzing the expression of Adcy1 mRNA in nervous system tissues of morphine tolerant mice. The mRNA expression of adenylyl cyclase isoforms and other downstream intracellular targets were analyzed in both central and peripheral nervous system tissues including brain stem (BS), trigeminal ganglion (TG), spinal cord (SC), dorsal root ganglion (DRG) and sciatic nerve (SN) after chronic morphine treatment using qRT-PCR. To induce morphine tolerance, morphine was administered twice daily (15 mg/kg, sc in saline) for five days. The overall fold change in gene expression was calculated for morphine tolerant mouse tissues compared to control saline treated mice (Supplemental Figure 1). An increased expression of Adcy1 is seen in SN, DRG, and TG, and a $>2$-fold increase was found in in the SC (Table 1). A >2-fold increase in mRNA expression was also seen in the SN for Adcy3, Adcy6 and Rapgef3 (Table 1). This data suggests AC1 may play a role in morphine tolerance in both the central and peripheral nervous systems. To further understand the physiological role of AC1 in tolerance and withdrawal during chronic morphine administration, pharmacological and gene knock-down strategies were implemented with behavioral assays.

\begin{tabular}{|l|l|l|l|l|l|l|c|}
\hline Gene & Tissue & $\begin{array}{c}\text { Fold } \\
\text { Change }\end{array}$ & \multicolumn{1}{|c|}{ Range } & Gene & Tissue & Fold change & Range \\
\hline Adcy1 & SN & 1.52 & 0.91 to 3.45 & Adcy8 & SN & 1.68 & 0.68 to 2.64 \\
\hline & DRG & 1.19 & 0.83 to 2.66 & & DRG & 1.31 & 1.12 to 1.60 \\
\hline & SC & 2.15 & 1.45 to 3.39 & & SC & 0.67 & 0.47 to 0.71 \\
\hline & BS & 0.35 & 0.11 to 0.45 & & BS & 0.44 & 0.23 to 0.56 \\
\hline & TG & 1.15 & 1.10 to 1.42 & & TG & 1.71 & 1.16 to 2.33 \\
\hline Adcy2 & SN & 0.71 & 0.60 to 1.80 & Prkaca & SN & 1.53 & 1.13 to 2.10 \\
\hline & DRG & 1.56 & 1.27 to 1.68 & & DRG & 1.52 & 1.30 to 1.91 \\
\hline & SC & 1.04 & 0.71 to 1.30 & & SC & 0.91 & 0.65 to 0.98 \\
\hline & BS & 0.54 & 0.32 to 0.65 & & BS & 0.5 & 0.34 to 0.61 \\
\hline & TG & 0.71 & 0.85 to 2.13 & & TG & 1.08 & 0.99 to 1.13 \\
\hline SN & 2.22 & 1.42 to 3.42 & Prkacb & SN & 1.42 & 1.14 to 1.90 \\
\hline & DRG & 1.45 & 1.14 to 1.66 & & DRG & 1.4 & 1.32 to 1.52 \\
\hline & SC & 0.54 & 0.36 to 0.63 & & SC & 0.68 & 0.50 to 0.81 \\
\hline & BS & 0.37 & 0.13 to 0.48 & & BS & 0.53 & 0.33 to 0.66 \\
\hline & TG & 1.11 & 1.01 to 1.35 & & TG & 1.17 & 0.99 to 1.23 \\
\hline SN & 1.81 & 0.83 to 2.20 & Rapgef3 & SN & 2.34 & 1.16 to 3.52 \\
\hline Adcy5 & DRG & 0.92 & 0.79 to 1.13 & & DRG & 1.25 & 1.07 to 1.76 \\
\hline & SC & 0.94 & 0.68 to 1.14 & & SC & 1.21 & 0.73 to 1.48 \\
\hline & BS & 0.58 & 0.37 to 0.77 & & BS & 0.56 & 1.37 to 1.78 \\
\hline & TG & 1.29 & 1.07 to 1.36 & & TG & 1.46 & 1.04 \\
\hline Adcy6 & SN & 2.13 & 1.09 to 3.16 & Rapgef4 & SN & & \\
\hline
\end{tabular}




\begin{tabular}{|l|l|l|l|l|l|l|l|}
\hline & DRG & 1.35 & 0.70 to 2.25 & & DRG & 1.47 & 1.22 to 1.56 \\
\hline & SC & 0.09 & 0.03 to 0.12 & & SC & 0.9 & 0.75 to 1.19 \\
\hline & BS & 0.64 & 0.46 to 1.00 & & BS & 0.8 & 0.75 to 0.83 \\
\hline & TG & 0.93 & 0.71 to 1.40 & & TG & 1.07 & 0.91 to 1.28 \\
\hline
\end{tabular}

Table 1. Altered levels of AC isoforms and downstream targets during morphine tolerance. Morphine tolerance was induced in mice by twice daily injections of $15 \mathrm{mg} / \mathrm{kg}$ morphine in saline (100 $\mu \mathrm{L}$, subcutaneous) for five days. Expression of each gene in sciatic nerve (SN), dorsal root ganglion (DRG), spinal cord (SC), brainstem (BS) and trigeminal ganglion (TG) was analyzed using qRT-PCR. The mean gene concentration within each tissue was first normalized to $18 S$ before being compared to the same tissue from saline treated mice resulting in overall fold change. Median fold change and the range of fold change values are reported ( $n=4$ /group).

\section{Systemic ST034307 administration attenuates morphine tolerance and withdrawal}

Previous research demonstrated ST034307 acts as an AC1 inhibitor and as an analgesic in a mouse chronic inflammatory pain model [4]. The data presented here also confirm the possible antinociceptive properties of ST034307. In both mechanical and thermal nociceptive tests, the peak threshold and latency measurements increased after intraperitoneal administration of ST034307 (Figure 1A, B). A significant difference in TPW latency was seen between vehicle and ST034307 over time (Figure 1B; repeated measures ANOVA with Bonferroni's post hoc test, $\mathrm{F}(1,12)=15.06, \mathrm{p}=0.0022, \mathrm{CI}_{15 \min }=1.282$ to 5.912$)$. This data demonstrates the peak antinociceptive action of ST034307 occurring around 15 minutes post injection, but this effect is fairly weak in naïve mice. So, any changes in thresholds seen during morphine tolerance testing should be due to AC1 inhibition and not analgesia caused by ST034307 administration.

Previous research demonstrated ST034307 acts as an AC1 specific inhibitor capable of blocking heterologous sensitization of AC1 after chronic MOR activation in vitro[4]. To determine if ST034307 attenuates morphine tolerance and opioid-induced hypersensitivity in vivo, mice were subjected to twice daily morphine injections $(10 \mathrm{mg} / \mathrm{kg}$ on day one increasing $10 \mathrm{mg} / \mathrm{kg}$ each day to a final concentration of $40 \mathrm{mg} / \mathrm{kg}$, sc) in combination with either an injection of vehicle or ST034307 (5 mg/kg, ip), 15 minutes post-morphine. MPW thresholds were measured before the start of injections (Figure 1C) and 30 minutes post morphine injection (Figure 1D) to measure opioid-induced hypersensitivity and morphine tolerance, respectively. Although the administration of ST034307 increased paw withdrawal thresholds after morphine administration had ceased after Day 4, no significant difference is seen between the two treatment groups premorphine (Figure 1C; two-way ANOVA with Bonferroni's post hoc test, $\mathrm{F}(1,16)=3.940, \mathrm{p}=$ 0.0646). Mice treated with ST034307 demonstrated significantly higher MPW thresholds after morphine injections compared to vehicle treated mice (Figure 1D; two-way ANOVA Bonferroni's post hoc test, $\mathrm{F}(1,16)=6.512$, $\mathrm{p}=0.0213)$, indicating that the pharmacological inhibition of AC1 can aid in the attenuation of tolerance. 
Intrathecal knockdown of Adcy1 attenuates morphine tolerance and opioid-induced hypersensitivity

An AAV9 viral vector strategy utilizing shRNA targeting to Adcy1 was used to reduce Adcy1 expression within the peripheral nervous system and spinal cord via intrathecal injection. To ensure the shRNA knockdown strategy of the AAV9-Adcy1 viral vector was successful, animals were sacrificed eight weeks post viral vector injections and SC and DRG tissues were collected. The mRNA copy numbers of Adcy1 were significantly reduced in AAV9-Adcy1 viral vector injected mice in both the SC (Figure 2A, unpaired t-test, $\mathrm{p}=0.0201$ ) and DRG (Figure 2A, unpaired t-test, $\mathrm{p}=0.0370$ ) compared to mice treated with the AAV9-scramble vector. Changes to the expression levels of Adcy5, Adcy8, Oprm1, and other genes involved in the AC/cAMP pathway (e.g. PKA, Epac) were also analyzed, but no significant differences were seen for any of these genes in either tissue (Figure 2B-F).

Since continued agonist stimulation of the MOR increases AC1/cAMP activity, the Adcy1 knockdown model was hypothesized to show an attenuation of morphine tolerance and opioidinduced hypersensitivity, but not necessarily acute morphine antinociception. An acute dose response curve indicated AAV9-Adcy1 and AAV9-scramble treated mice had similar antinociceptive effects of morphine (Figure 3A; two-way ANOVA, F $(1,18)=0.3231, \mathrm{p}=$ 0.5768). This suggests that a single administration of morphine remains equally effective after knockdown of AC1. Five weeks post viral vector injections, mice were administered morphine twice daily in saline (15 mg/kg, sc) and MPW thresholds were measured twice daily, before the morning injections of morphine (Figure 3B) and 30 minutes post injection (Figure 3C). On Day 6, MPW thresholds were taken 18 hours after last morphine injection (Figure 3B). AAV9Adcy1 injected mice had significantly higher MPW thresholds compared to AAV9-scramble injected mice both pre-morphine administration (Figure 3B; two-way ANOVA with Bonferroni's post hoc test, $\mathrm{F}(1,18)=7.323, \mathrm{p}=0.0145, \mathrm{CI}_{\text {Day6 }}=-1.933$ to -0.7565$)$ and post-morphine (Figure 3C; two-way ANOVA with Bonferroni's post hoc test, F $(1,18)=5.847, \mathrm{p}=0.0264$, $\mathrm{CI}_{\text {Day4 }}=-2.034$ to $-0.1778, \mathrm{CI}_{\text {Day5 }}=-2.211$ to -0.3548 ) indicating the knockdown of Adcy1 not only attenuates the development of morphine tolerance but also the development of opioidinduced hypersensitivity.

Using an escalating morphine tolerance model, mice were subjected to MPW latency testing while given twice daily injections of increasing doses of morphine in saline, starting with 10 $\mathrm{mg} / \mathrm{kg}$ on Day 1 and increasing by $10 \mathrm{mg} / \mathrm{kg}$ daily until reaching $40 \mathrm{mg} / \mathrm{kg}$ on Day 4. The escalating morphine tolerance paradigm was used because the development of tolerance or opioid-induced hypersensitivity can lead to increased pain in clinic, with the usual consequence of escalating doses of opioids, either by prescription or self-medication[19]. MPW thresholds were measured every AM before (Figure 3D) and 30 minutes post-morphine administration (Figure 3E). On Day 5 and Day 6, MPW thresholds were measured 18 hours and 42 hours after the last morphine dose, respectfully (Figure 3D). AAV9-Adcy1 injected mice exhibited significantly higher MPW thresholds than AAV9-scramble injected mice pre-morphine administration on Day 4, and on Days 5 and 6 when no morphine was administered (Figure 3D; two-way ANOVA with Bonferroni's post hoc test, $\mathrm{F}(1,18)=23.51, \mathrm{p}=0.0001, \mathrm{CI}_{\text {Day4 }}=-0.8649$ 
to $-0.03292, \mathrm{CI}_{\text {Day5 }}=-0.8556$ to $-0.02362, \mathrm{CI}_{\text {Day6 }}=-1.299$ to -0.4668$)$. However, no significant difference is seen in MPW thresholds post-morphine administration between AAV9-Adcy1 and AAV9-scramble injected mice (Figure 3E). This indicates that knockdown of Adcy1 significantly attenuates opioid-induced hypersensitivity as well as opioid withdrawal in the escalating morphine tolerance model.

Intrathecal knockdown of Adcy1 improves mechanical hypersensitivity and non-evoked behaviors after CFA injection in mice

Previous research has demonstrated that pharmacological inhibition of AC1 via ST034307 could provide analgesia in a mouse model of chronic inflammatory pain[4]. We devised a similar test for analgesic efficacy after Adcy1-shRNA treatment seven weeks after inoculation. One hind paw of each mouse was injected with CFA and MPW thresholds were measured three hours to one week after injection on both the injected (ipsilateral, Figure 4A) and non-injected (contralateral, Figure 4B) hind paws. AAV9-Adcy1 injected mice had significantly higher MPW thresholds than AAV9-scramble treated mice on both the CFA injected paw (Figure 4A; repeated measures ANOVA with Bonferroni's post hoc test, $\mathrm{F}(1,18)=6.157, \mathrm{p}=0.0232, \mathrm{CI}_{168 \mathrm{hrs}}=$ 0.8329 to -0.08993 ) and the uninjected (right) hind paw (Figure 4B; repeated measures ANOVA with Bonferroni's post hoc test, $\mathrm{F}(1,18)=9.148, \mathrm{p}=0.0073, \mathrm{CI}_{48 \mathrm{hrs}}=-1.384$ to -0.0513$)$. This data indicates gene knockdown of Adcy1 does provide some analgesic efficacy in the chronic inflammatory pain model 48 hours to one-week post-CFA administration.

During this stage of chronic inflammation, non-evoked measures of pain and animal well-being including burrowing and nesting were examined to gain a better understanding of the impact of AC1 expression on behavioral measures during chronic inflammation. Both AAV9-Adcy1 knockdown and AAV9-scramble treatment groups were subjected to burrowing testing three weeks and seven weeks post viral vector injections. No significant differences in burrowing behaviors were seen between the two treatment groups at the three weeks post viral vector injections (Figure 4C, Pre-CFA) but a significant difference was seen between the two treatment groups four days after CFA injection (Figure 4C, Post-CFA, two way ANOVA with Bonferroni's post hoc test; $\mathrm{F}(1,18)=16.66 ; \mathrm{p}=0.0007$; CIPre-CFA $=-16.16$ to 39.56, CI Post $\mathrm{CFA}=$ -55.73 to -0.01139). A significant difference was also seen between the pre-CFA and post-CFA burrowing results for the AAV9-Adcy1 viral vector treated group (Figure 4C, two-way ANOVA with Bonferroni's post hoc test; $\mathrm{F}(1,18)=16.66 ; \mathrm{p}=0.0007 ; \mathrm{CI}_{\text {Adcy } 1}=-83.03$ to -25.03$)$.

Nesting behaviors were also conducted seven weeks post viral vector injections. A significant difference in nesting scores was seen between AAV9-Adcy1 and AAV9-scramble injected mice (Figure 4D, Mann Whitney U test; $\mathrm{p}<0.0001$ ). Altogether, this data indicates the level of ongoing pain or discomfort may be decreased after AC1 knockdown and the loss of AC1 signaling may contribute greater functional motility during chronic pain.

Knockdown of Adcy1 does not alter mobility or thermal nociception in mice

Additional behavioral tests were performed in order to see if a reduction of AC1 expression would affect other animal behaviors. Mice were subjected to both rotarod and open field assessments and thermal paw withdrawal testing three and four weeks post viral-vector 
injections, respectively. For rotarod testing, the total time on rotarod (Figure 5A) and maximum speed reached (Figure 5B) were not significantly different between AAV9-scramble and AAV9Adcy1 mice. No significant difference was seen between AAV9-scramble and AAV9-Adcy1 mice during TPW testing (Figure 5C). In open field tests, no significant difference was seen between AAV9-Scramble and AAV9-Adcy1 viral vector injected mice in distance traveled (Figure 5C), velocity (Figure 5F) and change in orientation angle (Figure 5G;). However, a small yet significant difference was seen in time spent immobile (Figure 5E; unpaired t-test, $\mathrm{p}=$ 0.0433) indicating that AAV9-Adcy1 viral vector injected mice spent less time stationary compared to AAV9-scramble injected mice. Altogether, this data indicates the AAV9-Adcy1 shRNA does not cause any major mobility changes in mice.

AAV9-Adcy1 knockdown does not alter sciatic nerve conduction

Viral inoculation was confirmed by fluorescence microscopy and the presence of GFP (Figure 6A). GFP signal was visualized in the sciatic nerves of all inoculated mice. Both right and left sciatic nerves were isolated and C-fiber compound action potentials (CAPs) were performed eight weeks post viral vector injection and CAPs were recorded. The downregulation of Adcy1 did not have any impact on thresholds, amplitude, or conduction velocity of CAPs (Figure 6BD.)

\section{Discussion}

The present study investigated the role of AC1 in a mouse model with regards to opioid tolerance, opioid-induced hyperalgesia, and inflammatory pain after CFA injection. Although all of the underlying mechanisms behind tolerance and opioid-induced hyperalgesia are not currently known, increased AC1 expression and activity has been suggested to be one of the major causative agents [8]. Our results indicate pharmaceutical inhibition of AC1 using ST034307 reduced opioid tolerance and attenuated morphine-induced hypersensitivity after increasing opioid administration. Intrathecal knockdown of Adcy1 using a viral strategy was also effective at reducing morphine-induced hyperalgesia and withdrawal. The loss of Adcy1 expression increased mechanical paw withdrawal thresholds, and improved burrowing and nesting behaviors after CFA intraplantar injection. This data suggests a reduction in the activity or function of AC1 may represent a novel analgesic target in addition to improving opioid withdrawal in patients taking opioids.

To date, there are nine membrane-bound AC isoforms, AC1-AC9 characterized in mammals and all nine have been confirmed in the nervous system [34]. AC1 is present in the brain, particularly in the cortex, hippocampus, and cerebellum, and historically has been thought to play a large role in learning and memory [12; 45]. AC1 is also present in the spinal cord [41] and in TrkA positive neurons in the DRG of mice [18]. A global loss in AC1 activity results in attenuated nocifensive behaviors after formalin hind paw injection and reduces PCREB activation in the superficial dorsal horn of the spinal cord [41]. The mechanisms that drive chronic pain are thought to be associated with opioid tolerance and both phenomena may arise from similar changes in intracellular signaling pathways in the peripheral and/or central nervous systems [20]. Along these lines, chronic morphine has been shown to produce a hypertrophied 
state of AC activity for AC 1, 6 and 8 in vitro [2]. The hypothesis that a selective AC1 inhibitor, ST034307, could also attenuate the development of morphine tolerance and hypersensitivity using an escalating dose paradigm was tested in our studies. Data presented here indicate that opioid-induced hyperalgesia was significantly attenuated after pharmacological inhibition of AC1, suggesting elevated activity of AC1 is responsible for the enhanced mechanical sensitivity upon cessation of daily morphine treatment.

Hypersensitivity and hyperalgesia seen in chronic pain and drug-induced hypersensitivity states most likely occur on multiple levels along sensory transmission pathways, from peripheral afferents, spinal cord synapses, and connectivity across midbrain and cortical cells. In chronic pain and opioid tolerant states, increased AC activity has been reported across the brain [28; 47] in addition to the spinal cord [42] and primary afferents [3; 46] which are thought to contribute to enhanced neurotransmission of nociceptive circuits. In order to determine if a localized decrease specifically targeted to AC1 activity in the spinal cord and primary afferent neurons could attenuate to opioid tolerance and inflammatory chronic pain, a genetic knockdown approach was used instead of a pharmacological one. Intrathecal delivery of AAV9 serotypes in live mice yield a high efficacy of transduction efficiency in DRG and lumbar spinal cord, while yielding sporadic labeling in the cortex and other peripheral tissues [32]. Static dosing of morphine (15 mg/kg, 2x daily, 5 days) and escalating doses of morphine over four days (10-40 $\mathrm{mg} / \mathrm{kg}$, 2x daily) both resulted in enhanced baseline mechanical sensitivity during the course of morphine administration. After intrathecal administration of AAV9-Adcy1, mice had higher mechanical paw withdrawal thresholds before (pre) and 30 minutes after (post) morphine administration. However, the acute morphine antinociception was not changed compared to control vector mice suggesting no change in acute pain responses which is similar to data obtained from AC1 knockout mice[41]. This important distinction between a lack of antinociception after acute morphine delivery and a significant enhancement of paw withdrawal thresholds after chronic morphine administration, indicate that adenylyl cyclase hypertrophy occurs after repeated stimulation of the MOR, and not after a single dose of an opioid, which has been a proposed paradigm for many years[43].

Systemic delivery of pharmacological inhibitors of AC1 have reduced hypersensitivity in neuropathic and inflammatory pain models in mice [4; 39]. The hypothesis that genetic knockdown of AC1 in the spinal cord and DRG could also attenuate inflammatory pain in mice was tested in our studies. Using a CFA model, AAV9-Adcy1 mice had higher mechanical paw withdrawal thresholds compared to control mice seven days after CFA injection. This attenuation of mechanical hyperalgesia was also seen on the contralateral (uninjected) hind paws. During chronic pain states, it is possible that anatomical sites nearby also become sensitized to painful or non-painful stimulation as reported in previous rodent studies[6; 15]. The inhibition of AC1 appeared to attenuate mechanical hypersensitivity on either the ipsilateral or contralateral hindpaws, which indicate that pharmaceuticals targeting AC1 could also help attenuate pain sensitization beyond the primary zone of injury. The lack of analgesia seen during the initial phases after CFA administration (3-24 hrs), could be due to the role of adenylyl cyclases in enhanced transcription of pro-inflammatory molecules, which could take several days to 
manifest[35]. Alternatively, those results may be explained by the tissue specificity or overall level of the Adcy1 knockdown when compared to the AC1 knockout mice[41].

Spontaneous pain and animal wellbeing after initiation of chronic pain is less frequently investigated than evoked measures, so our studies incorporated alternative testing measures. Studies have shown burrowing and nesting tests can be used to evaluate spontaneous pain or tonic pain in rodents [14; 30]. Data presented here indicate no appreciable differences between AAV9-Adcy1 and AAV9-scramble mice in burrowing behaviors prior to CFA injection. However, four days after CFA induction, there is a significant improvement in burrowing behavior in AAV9-Adcy1 treated mice. A similar difference was also seen in the nesting scores after CFA induction, with AAV9-Adcy1 treated mice demonstrating significantly higher nesting scores than control mice. In previous studies, burrowing behavior is reduced in CFA inflammatory pain models in rats and can be reversed by ibuprofen[1]. Similarly, nesting behaviors are attenuated after CFA injection in mice which can be reversed by ketoprofen or low doses of morphine[31]. It is notable that no significant differences were detected between AAV9-Adcy1 and AAV9-scramble mice in either the rotarod, thermal paw withdrawal latencies, or open field testing parameters, indicating intrathecal knockdown of AC1 does not affect acute thermal pain thresholds or affect general ambulatory behaviors. Transcriptional knockdown of AC1 in the sciatic nerves of mice was not measured, but significant changes in C-fiber compound action potential properties were not observed in this study. These data indicate behavioral changes seen in the AAV9-Adcy1 animals may be restricted to the spinal cord and/or DRG, or loss of AC1 function does not impact axonal propagation of C-fiber action potentials.

In conclusion, small molecule inhibition of AC1 with ST034307 reduced morphine tolerance and hyperalgesia in mice. Similarly, knockdown of AC1 in the spinal cord and DRG reduced opioidinduced hypersensitivity after chronic administration of morphine in mice. Additionally, behavioral differences seen after Adcy1 reduction appear specific to chronic pain-related behaviors, as animal locomotion and acute nociception were unaffected compared to controls. These studies suggest sensitized AC1 may represent a novel pharmaceutical target for the reduction of chronic pain and the attenuation of opioid-mediated adverse effects such as hyperalgesia. Further research into the intracellular targets of AC1 may provide new opportunities for new therapeutics in the future.

\section{Acknowledgements}

Author contributions: Performed experiments and analyzed data: K.J, A.D. A.E. and A.H.K. Conceived experiments, designed and directed the studies: A.H.K. and V.J.W. Wrote the manuscript: K.J, A.D., V.J.W. and A.H.K.

This work was supported by grants from the National Institute of Drug Abuse (K01DA042902; A.H.K), and the Summer Undergraduate Research Program from the University of Minnesota (A.D.) and the TRIO McNair Scholars Program from the College of St. Scholastica (A.E.). 


\section{References}

[1] Andrews N, Legg E, Lisak D, Issop Y, Richardson D, Harper S, Pheby T, Huang W, Burgess $\mathrm{G}$, Machin I, Rice AS. Spontaneous burrowing behaviour in the rat is reduced by peripheral nerve injury or inflammation associated pain. Eur J Pain 2012;16(4):485-495.

[2] Avidor-Reiss T, Nevo I, Saya D, Bayewitch M, Vogel Z. Opiate-induced adenylyl cyclase superactivation is isozyme-specific. J Biol Chem 1997;272(8):5040-5047.

[3] Bavencoffe A, Li Y, Wu Z, Yang Q, Herrera J, Kennedy EJ, Walters ET, Dessauer CW. Persistent Electrical Activity in Primary Nociceptors after Spinal Cord Injury Is Maintained by Scaffolded Adenylyl Cyclase and Protein Kinase A and Is Associated with Altered Adenylyl Cyclase Regulation. J Neurosci 2016;36(5):1660-1668.

[4] Brust TF, Alongkronrusmee D, Soto-Velasquez M, Baldwin TA, Ye Z, Dai M, Dessauer CW, van Rijn RM, Watts VJ. Identification of a selective small-molecule inhibitor of type 1 adenylyl cyclase activity with analgesic properties. Sci Signal 2017;10(467).

[5] Cheah M, Fawcett JW, Andrews MR. Assessment of Thermal Pain Sensation in Rats and Mice Using the Hargreaves Test. Bio Protoc 2017;7(16).

[6] Chen KH, Yang CH, Juang SE, Huang HW, Cheng JK, Sheen-Chen SM, Cheng JT, Lin CR. Pulsed radiofrequency reduced complete Freund's adjuvant-induced mechanical hyperalgesia via the spinal c-Jun N-terminal kinase pathway. Cell Mol Neurobiol 2014;34(2):195-203.

[7] Collier HOJ, Francis DL. Morphine abstinence is associated with increased brain cyclic AMP. Nature 1975;255:159-161.

[8] Corder G, Doolen S, Donahue RR, Winter MK, Jutras BL, He Y, Hu X, Wieskopf JS, Mogil JS, Storm DR, Wang ZJ, McCarson KE, Taylor BK. Constitutive $\mu$-Opioid Receptor Activity Leads to Long-term Endogenous Analgesia and Dependence. Science 2013;341(6152):1394-1399.

[9] Crain SM, Makman MH. Electrophysiologic responses and adenylate cyclase activities of mouse spinal cord-dorsal root ganglion explants rendered tolerant by chronic exposure to morphine or pertussis toxin. Adv Exp Med Biol 1987;221:331-344.

[10] Crispim Junior CF, Pederiva CN, Bose RC, Garcia VA, Lino-de-Oliveira C, Marino-Neto J. ETHOWATCHER: validation of a tool for behavioral and video-tracking analysis in laboratory animals. Comput Biol Med 2012;42(2):257-264.

[11] Deacon R. Assessing burrowing, nest construction, and hoarding in mice. J Vis Exp 2012(59):e2607.

[12] Defer N, Best-Belpomme M, Hanoune J. Tissue specificity and physiological relevance of various isoforms of adenylyl cyclase. Am J Physiol Renal Physiol 2000;279(3):F400-416.

[13] Fairbanks CA. Spinal delivery of analgesics in experimental models of pain and analgesia. Adv Drug Deliv Rev 2003;55(8):1007-1041.

[14] Gaskill BN, Karas AZ, Garner JP, Pritchett-Corning KR. Nest building as an indicator of health and welfare in laboratory mice. J Vis Exp 2013(82):51012.

[15] Griffioen MA, Dernetz VH, Yang GS, Griffith KA, Dorsey SG, Renn CL. Evaluation of dynamic weight bearing for measuring nonevoked inflammatory hyperalgesia in mice. Nurs Res 2015;64(2):81-87.

[16] Griggs RB, Laird DE, Donahue RR, Fu W, Taylor BK. Methylglyoxal Requires AC1 and TRPA1 to Produce Pain and Spinal Neuron Activation. Front Neurosci 2017;11:679. 
[17] Griggs RB, Santos DF, Laird DE, Doolen S, Donahue RR, Wessel CR, Fu W, Sinha GP, Wang P, Zhou J, Brings S, Fleming T, Nawroth PP, Susuki K, Taylor BK. Methylglyoxal and a spinal TRPA1-AC1-Epac cascade facilitate pain in the $\mathrm{db} / \mathrm{db}$ mouse model of type 2 diabetes. Neurobiol Dis 2019;127:76-86.

[18] Haupt C, Langhoff J, Huber AB. Adenylate Cyclase 1 modulates peripheral nerve branching patterns. Mol Cell Neurosci 2010;45(4):439-448.

[19] Hayhurst CJ, Durieux ME. Differential Opioid Tolerance and Opioid-induced Hyperalgesia: A Clinical Reality. Anesthesiology 2016;124(2):483-488.

[20] Joseph EK, Reichling DB, Levine JD. Shared mechanisms for opioid tolerance and a transition to chronic pain. J Neurosci 2010;30(13):4660-4666.

[21] KI V, H W, SW K, E Z, MJ P, KA S, M Z. Genetic reduction of chronic muscle pain in mice lacking calcium/calmodulin-stimulated adenylyl cyclases. Molecular pain 2006;2(7).

[22] Klein AH, Mohammad HK, Ali R, Peper B, Wilson SP, Raja SN, Ringkamp M, Sweitzer S. Overexpression of $\mu$-Opioid Receptors in Peripheral Afferents, but Not in Combination with Enkephalin, Decreases Neuropathic Pain Behavior and Enhances Opioid Analgesia in Mouse. Anesthesiology 2018;128(5):967-983.

[23] Klein AH, Sawyer CM, Zanotto KL, Ivanov MA, Cheung S, Carstens MI, Furrer S, Simons CT, Slack JP, Carstens E. A tingling sanshool derivative excites primary sensory neurons and elicits nocifensive behavior in rats. J Neurophysiol 2011;105(4):1701-1710.

[24] Klein AH, Trannyguen M, Joe CL, Iodi CM, Carstens E. Thermosensitive transient receptor potential (TRP) channel agonists and their role in mechanical, thermal and nociceptive sensations as assessed using animal models. Chemosens Percept 2015;8(2):96-108.

[25] Li S, Lee ML, Bruchas MR, Chan GC, Storm DR, Chavkin C. Calmodulin-Stimulated Adenylyl Cyclase Gene Deletion Affects Morphine Responses. Molecular Pharmacology 2006;70(5):1742-1749.

[26] Li X-H, Chen Q-Y, Zhuo M. Neuronal Adenylyl Cyclase Targeting Central Plasticity for the Treatment of Chronic Pain. Neurotherapeutics 2020.

[27] Liang DY, Li X, Clark JD. 5-hydroxytryptamine type 3 receptor modulates opioid-induced hyperalgesia and tolerance in mice. Anesthesiology 2011;114(5):1180-1189.

[28] Liauw J, Wu LJ, Zhuo M. Calcium-stimulated adenylyl cyclases required for long-term potentiation in the anterior cingulate cortex. J Neurophysiol 2005;94(1):878-882.

[29] Makman MH, Dvorkin B, Crain SM. Modulation of adenylate cyclase activity of mouse spinal cord-ganglion explants by opioids, serotonin and pertussis toxin. Brain Res 1988;445(2):303-313.

[30] Muralidharan A, Kuo A, Jacob M, Lourdesamy JS, Carvalho LM, Nicholson JR, Corradini L, Smith MT. Comparison of Burrowing and Stimuli-Evoked Pain Behaviors as EndPoints in Rat Models of Inflammatory Pain and Peripheral Neuropathic Pain. Front Behav Neurosci 2016;10:88.

[31] Negus SS, Neddenriep B, Altarifi AA, Carroll FI, Leitl MD, Miller LL. Effects of ketoprofen, morphine, and kappa opioids on pain-related depression of nesting in mice. Pain 2015;156(6):1153-1160.

[32] Schuster DJ, Dykstra JA, Riedl MS, Kitto KF, Honda CN, McIvor RS, Fairbanks CA, Vulchanova L. Visualization of spinal afferent innervation in the mouse colon by AAV8mediated GFP expression. Neurogastroenterol Motil 2013;25(2):e89-100. 
[33] Sharma S, Klee W, Nirenberg M. Dual regulation of adenylate cyclase accounts for narcotic dependence and tolerance. Proceedings of the National Academy of Sciences 1975;72(8):3092-3096.

[34] Sunahara RK, Dessauer CW, Gilman AG. Complexity and diversity of mammalian adenylyl cyclases. Annu Rev Pharmacol Toxicol 1996;36:461-480.

[35] Tarnawski L, Reardon C, Caravaca AS, Rosas-Ballina M, Tusche MW, Drake AR, Hudson LK, Hanes WM, Li JH, Parrish WR, Ojamaa K, Al-Abed Y, Faltys M, Pavlov VA, Andersson U, Chavan SS, Levine YA, Mak TW, Tracey KJ, Olofsson PS. Adenylyl Cyclase 6 Mediates Inhibition of TNF in the Inflammatory Reflex. Front Immunol 2018;9:2648.

[36] Vadakkan K, Wang H, Ko S, Zastepa E, Petrovic M, Sluka K, Zhuo M. Genetic reduction of chronic muscle pain in mice lacking calcium/calmodulin-stimulated adenylyl cyclases. Mol Pain 2006;2:7.

[37] Villacres EC, Wong ST, Chavkin C, Storm DR. Type I Adenylyl Cyclase Mutant Mice Have Impaired Mossy Fiber Long-Term Potentiation. The Journal of Neuroscience 1998;18(9):3186-3194.

[38] Vulchanova L, Schuster DJ, Belur LR, Riedl MS, Podetz-Pedersen KM, Kitto KF, Wilcox GL, McIvor RS, Fairbanks CA. Differential adeno-associated virus mediated gene transfer to sensory neurons following intrathecal delivery by direct lumbar puncture. Mol Pain 2010;6:31.

[39] Wang H, Xu H, Wu LJ, Kim SS, Chen T, Koga K, Descalzi G, Gong B, Vadakkan KI, Zhang X, Kaang BK, Zhuo M. Identification of an adenylyl cyclase inhibitor for treating neuropathic and inflammatory pain. Sci Transl Med 2011;3(65):65ra63.

[40] Wang $\mathrm{H}$, Zhang $\mathrm{M}$. The role of $\mathrm{Ca}^{2+}$-stimulated adenylyl cyclases in bidirectional synaptic plasticity and brain function. Reviews of the Neurosciences 2012;23(1):67-78.

[41] Wei F, Qiu CS, Kim SJ, Muglia L, Maas JW, Pineda VV, Xu HM, Chen ZF, Storm DR, Muglia LJ, Zhuo M. Genetic elimination of behavioral sensitization in mice lacking calmodulin-stimulated adenylyl cyclases. Neuron 2002;36(4):713-726.

[42] Wei F, Vadakkan KI, Toyoda H, Wu LJ, Zhao MG, Xu H, Shum FW, Jia YH, Zhuo M. Calcium calmodulin-stimulated adenylyl cyclases contribute to activation of extracellular signal-regulated kinase in spinal dorsal horn neurons in adult rats and mice. J Neurosci 2006;26(3):851-861.

[43] Williams JT, Christie MJ, Manzoni O. Cellular and synaptic adaptations mediating opioid dependence. Physiol Rev 2001;81(1):299-343.

[44] Williams JT, Ingram SL, Henderson G, Chavkin C, von Zastrow M, Schulz S, Koch T, Evans CJ, Christie MJ. Regulation of $\mu$-opioid receptors: desensitization, phosphorylation, internalization, and tolerance. Pharmacol Rev 2013;65(1):223-254.

[45] Wu ZL, Thomas SA, Villacres EC, Xia Z, Simmons ML, Chavkin C, Palmiter RD, Storm DR. Altered behavior and long-term potentiation in type I adenylyl cyclase mutant mice. Proc Natl Acad Sci U S A 1995;92(1):220-224.

[46] Yue X, Tumati S, Navratilova E, Strop D, St John PA, Vanderah TW, Roeske WR, Yamamura HI, Varga EV. Sustained morphine treatment augments basal CGRP release from cultured primary sensory neurons in a Raf-1 dependent manner. Eur J Pharmacol 2008;584(2-3):272-277. 
[47] Zachariou V, Liu R, LaPlant Q, Xiao G, Renthal W, Chan GC, Storm DR, Aghajanian G, Nestler EJ. Distinct roles of adenylyl cyclases 1 and 8 in opiate dependence: behavioral, electrophysiological, and molecular studies. Biol Psychiatry 2008;63(11):1013-1021. 


\section{Figures}
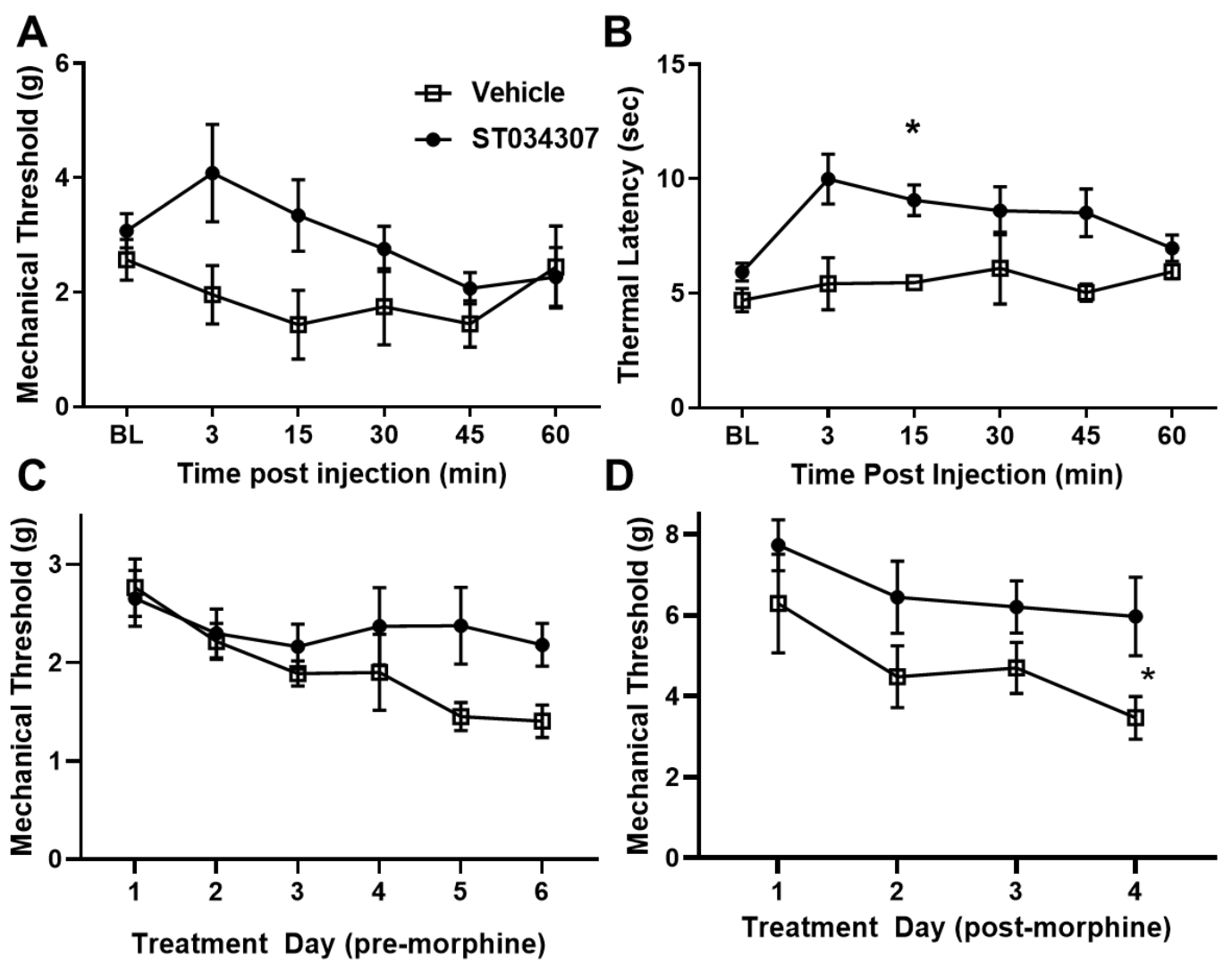

Figure 1. ST034307 Produces Mechanical and Thermal Antinociception and Attenuates Morphine Tolerance. To obtain mechanical thresholds and thermal paw withdrawal latencies , mice were given intraperitoneal injections of vehicle $(\square)$ or ST034307 (•) following baseline measurements (BL). (A) No significant analgesic differences were seen between vehicle and ST034307 treated mice. (B) A significant difference in thermal paw withdrawal was seen between vehicle and ST034307 treated mice (repeated measures ANOVA with Bonferroni's post hoc test, $\mathrm{F}(1,12)=15.06, \mathrm{p}=0.0022, \mathrm{CI}_{15 \min }=1.282$ to 5.912). To induce morphine tolerance, mice received twice daily injections of morphine $(10 \mathrm{mg} / \mathrm{kg}$ on day 1 increasing to $40 \mathrm{mg} / \mathrm{kg}$ by day 4, subcutaneous, $100 \mathrm{uL}$ ) along with an injection of either vehicle or ST034307 (5 mg/kg, intraperitoneal, $100 \mathrm{uL}) 15$ minutes post-morphine. BL measurements were measured every morning before morphine injection (C) and 30 minutes post injection (D) with day 5 and day 6 thresholds measured $\sim 18$ hours and $\sim 42$ hours, respectfully, after last morphine injection. MPW thresholds pre-morphine were not significantly different between the two treatment groups $(\mathrm{C}$; two-way ANOVA with Bonferroni's post hoc test, $\mathrm{F}(1,16)=3.940$, $\mathrm{p}=0.0646)$ but mice given ST034307 had significantly higher MPW thresholds compared to vehicle treated post-morphine (D; two-way ANOVA Bonferroni’s post hoc test, F $(1,16)=6.512, \mathrm{p}=0.0213$ ). Asterisk indicates statistical significance $(\mathrm{p}<0.05)$. Data presented as mean \pm SEM with an $n=4-$ 10/group. 
A

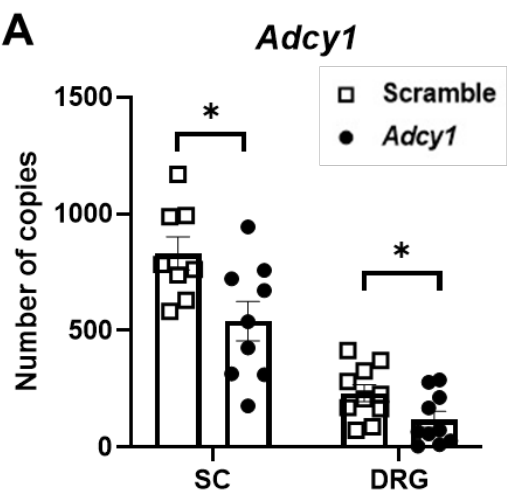

D

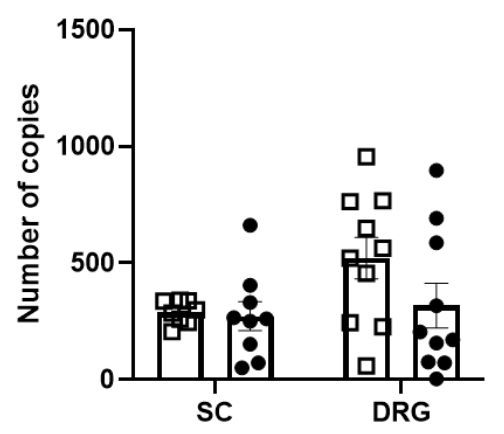

B

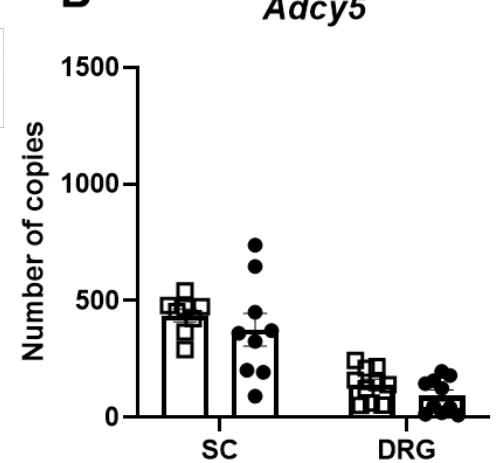

E

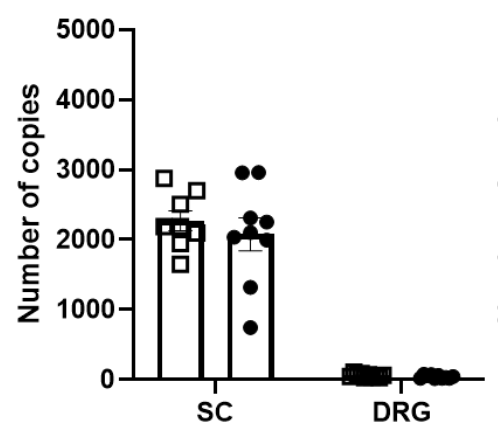

C $\quad$ Adcy8

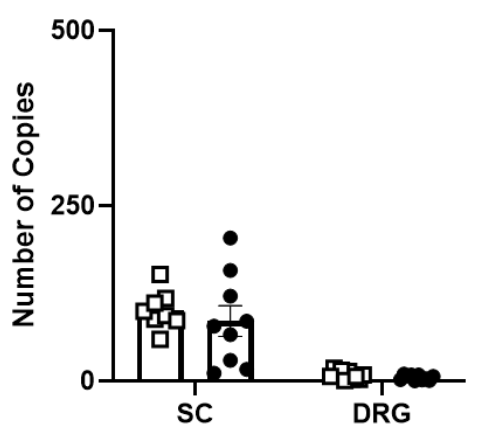

$\mathbf{F}$

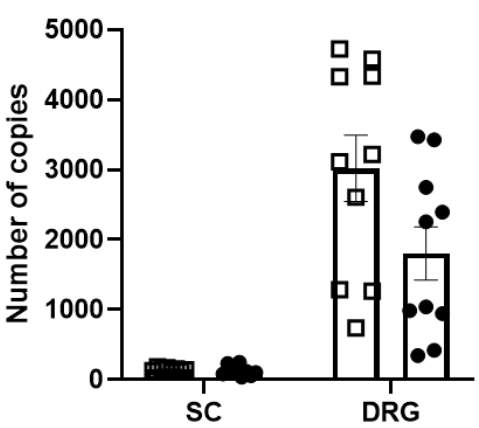

Figure 2. Adcy1 expression is significantly decreased in the spinal cord and dorsal root ganglia after shRNA knockdown. Eight weeks after AAV9-GFP-U6-m-Adcy1-shRNA or AAV9-GFP-U6-scramble-shRNA intrathecal injection, qRT-PCR analysis was performed for Adcy1 (A), Adcy5 (B), Adcy8 (C), Oprm1 (D), Rapgef3 (E), and Rapgef4 (F) within the spinal cord (SC) and dorsal root ganglia (DRG). Adcy1 was significantly decreased in AAV9-Adcy1 (•) vector injected mice in both SC (A: unpaired t-test, $\mathrm{p}=0.0201$ ) and DRG (unpaired t-test, $\mathrm{p}=$ 0.0370) compared to AAV9-scramble ( $\square$ ) vector injected mice. Asterisk indicates statistical significance $(\mathrm{p}<0.05)$. Data presented as mean \pm SEM with an $n=8-10$ /group. 

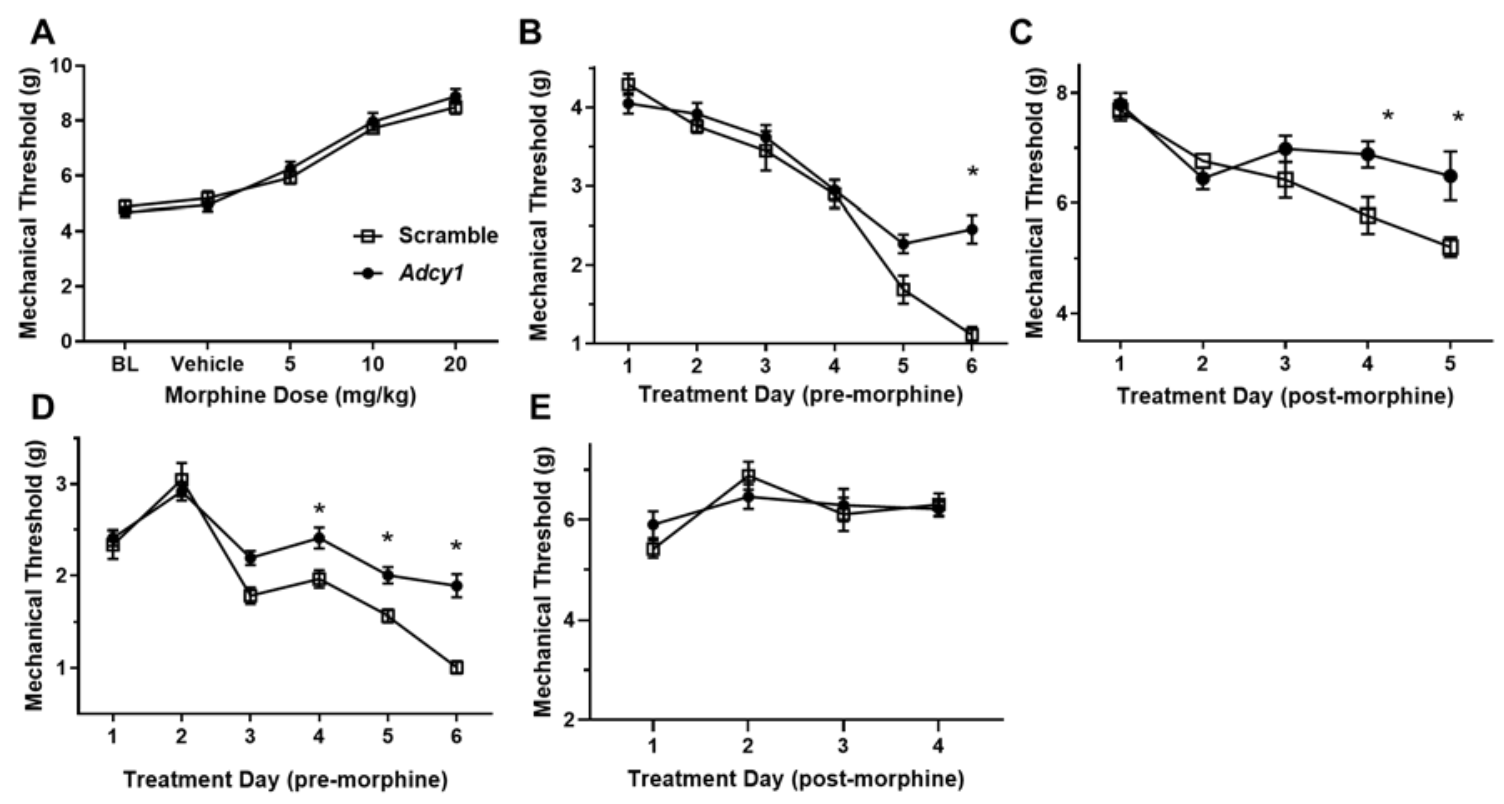

Figure 3. Intrathecal shRNA knockdown of Adcy1 attenuates morphine tolerance and morphine induced hypersensitivity in mice. MPW thresholds were measured after intrathecal injection of either AAV9-GFP-U6-m-Adcy1-shRNA (•) or AAV9-GFP-U6-scramble-shRNA ( $\square$ ) four to six weeks post viral vector injections. During morphine dose response (A), baseline (BL) thresholds were measured before mice were given injections of vehicle. Increasing doses of morphine in saline were administered and MPW thresholds were measured 30 minutes post injection. No significant differences were seen between the two treatment groups. In a morphine tolerance paradigm, mice were injected twice daily with $15 \mathrm{mg} / \mathrm{kg}$ morphine in saline for five days (B-C) or were administered twice daily morphine in saline injections starting with $10 \mathrm{mg} / \mathrm{kg}$ and increasing by $10 \mathrm{mg} / \mathrm{kg}$ every day for four days until reaching $40 \mathrm{mg} / \mathrm{kg}$ on day four (D-E). Baseline measurements were taken every morning before and 30 minutes after morphine administration, with treatment day six (6) measurements taken $\sim 18$ hours after last morphine administration (B) and with MPW thresholds on days five and six measured $\sim 18$ hours and $\sim 42$ hours post morphine injection, respectfully (D). AAV9-Adcy1 viral vector injected mice had significantly higher MPW thresholds during morphine tolerance testing compared to AAV9scramble injected mice both pre-morphine (B; two-way ANOVA with Bonferroni's post hoc test, $\mathrm{F}(1,18)=7.323, \mathrm{p}=0.0145, \mathrm{CI}_{\text {Day6 }}=-1.933$ to -0.7565$)$ and post-morphine $(\mathrm{C}$; two-way ANOVA with Bonferroni's post hoc test, $\mathrm{F}(1,18)=5.847, \mathrm{p}=0.0264, \mathrm{CI}_{\text {Day4 }}=-2.034$ to $0.1778, \mathrm{CI}_{\text {Day5 }}=-2.211$ to -0.3548$)$. AAV9-Adcy1 viral vector injected mice had significantly higher MPW thresholds during baseline measurements of escalating morphine tolerance compared to AAV9-scramble injected mice pre-morphine (D; two-way ANOVA with Bonferroni's post hoc test, $\mathrm{F}(1,18)=23.51, \mathrm{p}=0.0001, \mathrm{CI}_{\text {Day4 }}=-0.8649$ to -0.03292 , $\mathrm{CI}_{\text {Day } 5}=$ 0.8556 to $-0.02362, \mathrm{CI}_{\text {Day6 }}=-1.299$ to -0.4668 ). (E) No significant difference in morphine efficacy is seen during escalating morphine tolerance. Asterisk indicates statistical significance $(p<0.05)$. Data presented as mean \pm SEM with an $n=10$ /group. 

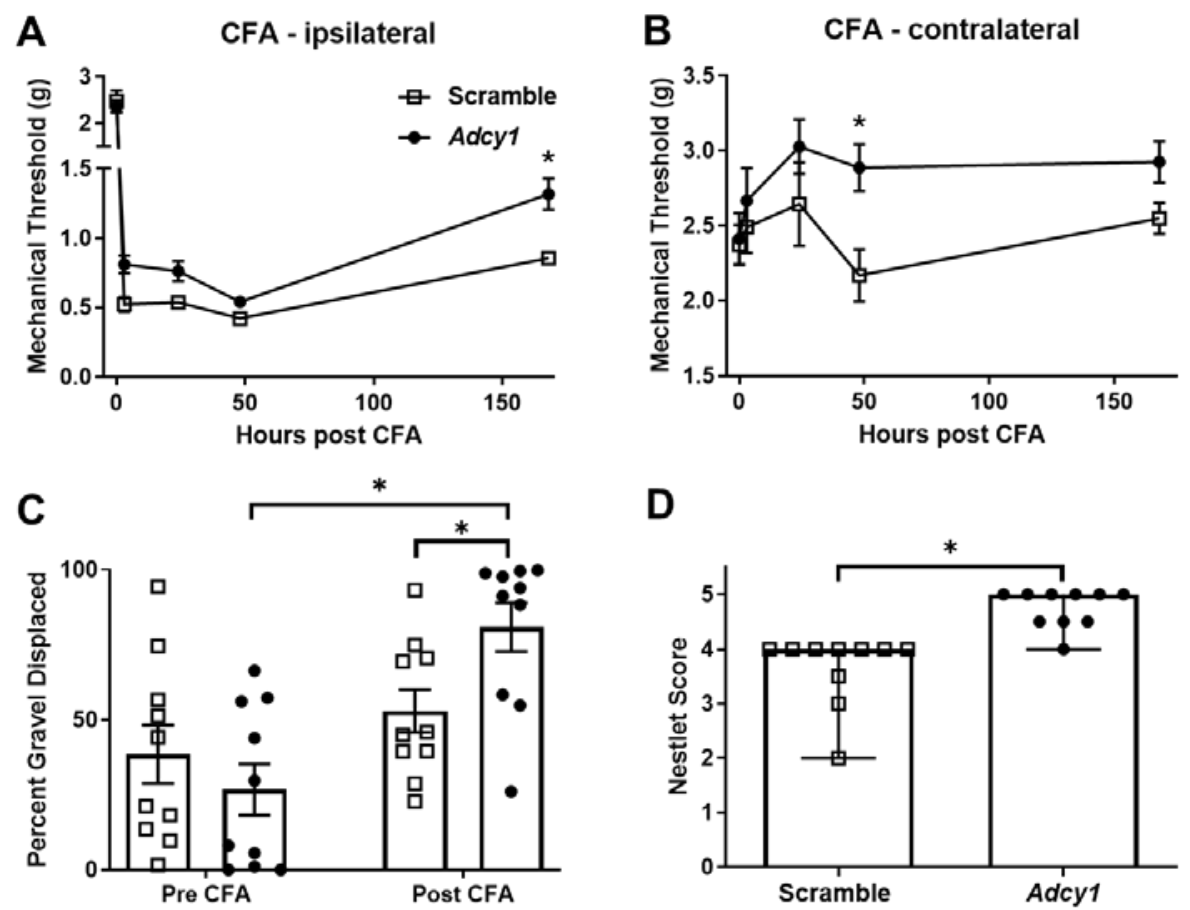

Figure 4. Adcy1 intrathecal knockdown provides analgesia in mice with CFA induced inflammatory pain. Seven weeks post AAV9-GFP-U6-m-Adcy1-shRNA (•) or AAV9-GFPU6-scramble-shRNA AAV9-scramble (口) injections, baseline MPW thresholds were measured before the left hind paw was injected with $20 \mu \mathrm{L}$ undiluted CFA. MPW thresholds were then measured 3 hours, one day, two days, and one week post CFA injection on both the injected (ipsilateral) hind paw (A) and the uninjected (contralateral) hind paw (B). AAV9-Adcy1 viral vector injected mice had significantly higher MPW thresholds than AAV9-scramble injected mice ( $\square$ ) on the injected paw (A; repeated measures ANOVA with Bonferroni's post hoc test, F $(1,18)=6.157, \mathrm{p}=0.0232, \mathrm{CI}_{168 \mathrm{rr}}=-0.8329$ to -0.08993$)$, and on the CFA uninjected paw (B; repeated measures ANOVA with Bonferroni's post hoc test, $\mathrm{F}(1,18)=9.148, \mathrm{p}=0.0073, \mathrm{CI}_{48 \mathrm{hrs}}$ $=-1.384$ to -0.0513). (C) AAV9-Adcy1 and AAV9-scramble viral vector injected mice underwent burrowing testing three weeks post viral vector injections (Pre-CFA) and again seven weeks post viral vector injection (Post-CFA). AAV9-Adcy1 viral vector injected mice had significantly higher percent gravel displaced during burrowing testing post-CFA than AAV9-scramble injected mice (C; two way ANOVA with Bonferroni's post hoc test; F $(1,18)=16.66$; $\mathrm{p}=0.0007$; CI Ire- $_{\text {re }}$ $\mathrm{CFA}=-16.16$ to 39.56 , CIPost $\mathrm{CFA}=-55.73$ to -0.01139 ) and also significantly higher percent gravel displaced than their pre-CFA activity (two-way ANOVA with Bonferroni's post hoc test; F (1, 18) $=16.66 ; \mathrm{p}=0.0007 ; \mathrm{CI}_{A d c y 1}=-83.03$ to -25.03 ). (D) Nesting behavioral measures began seven weeks post viral vector injections corresponding to 3 days post CFA injection. AAV9Adcy1 viral vector injected mice had significantly higher nesting scores compared to AAV9scramble injected mice (Mann Whitney U test; $\mathrm{p}<0.0001$ ). Asterisk indicates statistical significance $(\mathrm{p}<0.05)$. Data in (D) presented as Median with Range, all others presented as mean \pm SEM with $n=10$ /group). 

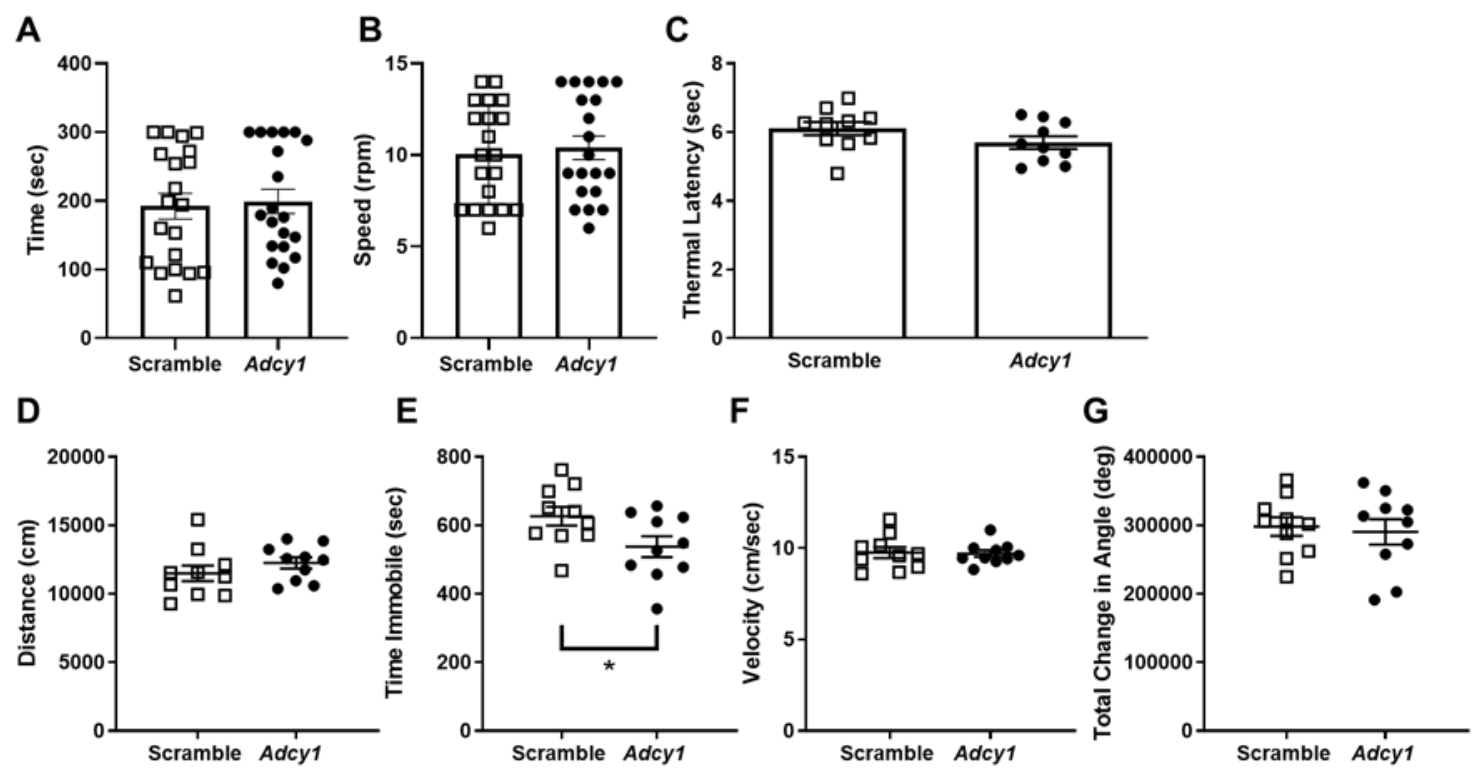

Figure 5. Animal mobility, thermal sensitivity and open field behaviors are not affected in mice with intrathecal knockdown of Adcy1. Three to four weeks post AAV9-GFP-U6-mAdcy1-shRNA (•) or AAV9-GFP-U6-scramble-shRNA ( $\square$ ) intrathecal injections, mice underwent behavioral assessments to gauge mobility and the presence of deficits prior to morphine testing. For rotarod testing (A, B), mice were placed on the rotarod with an initial speed of $4 \mathrm{rpm}$ increasing $1 \mathrm{rpm}$ every 30 seconds to a maximum of $14 \mathrm{rpm}$. The maximum time (A) and revolutions per minute (B) were not significantly different across treatment groups. (C) For thermal paw withdrawal latency testing no significant difference is seen between AAV9scramble and AAV9-Adcy1 mice. For open field assessment (D-G), mice were placed inside arena and activity was recorded for 30 minutes. Distance traveled in $\mathrm{cm}(\mathrm{D})$, time spent immobile in seconds (unpaired t-test, $p=0.0433)(E)$, velocity in centimeters per second $(F)$ and change in orientation angle in degrees $(\mathrm{G})$ were all calculated for both AAV9-scramble and AAV9-Adcy1 vector injected mice. No significant differences were seen between the two treatment groups in distance traveled, change in orientation angle and velocity. Data presented as mean \pm SEM with an $n=10$ /group. 

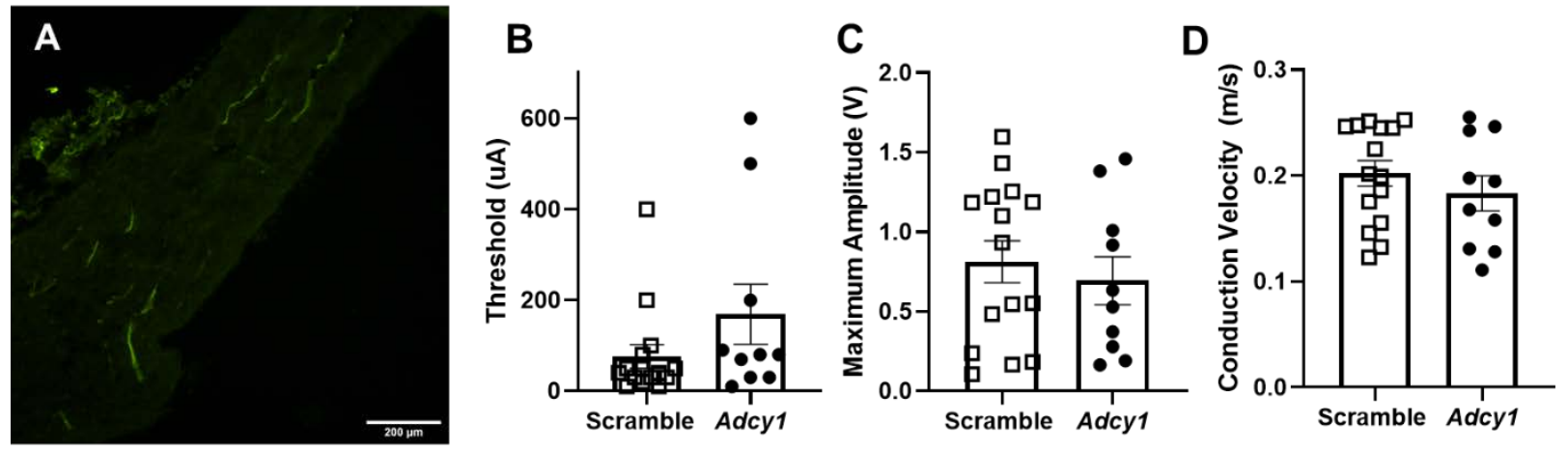

Figure 6. Knockdown of Adcy1 does not impact sciatic nerve conduction. Eight weeks post intrathecal inoculation with either AAV9-GFP-U6-m-Adcy1-shRNA (•) or AAV9-GFP-U6scramble-shRNA ( $\square)$, sciatic nerves were removed and used for compound action potential recordings. (A) GFP signal visualized by fluorescence microscopy. Scale bar $=200$ microns. The electrical thresholds (B), maximum CAP amplitude (C), and conduction velocity (D), were not significantly different between groups. Data presented as mean \pm SEM with $n=10$-15/group. 


\section{Supplemental Files}
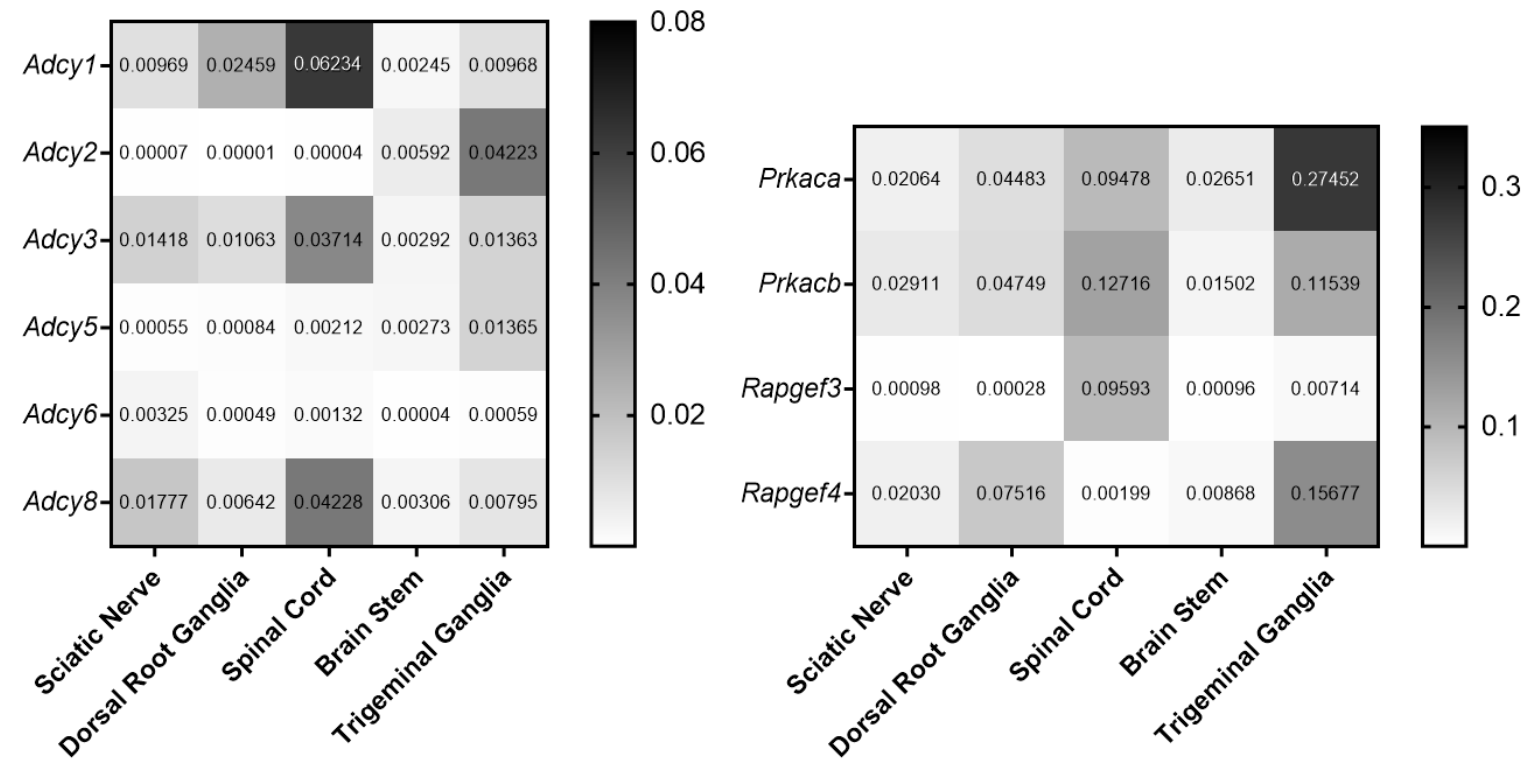

Supplemental Figure 1. Heat map of genes expressed in saline-treated mice. (A) Adenylyl cyclases 1, 2, 3, 5, 6, and 8. (B) Protein kinase A catalytic (Prkaca) and regulatory subunits (Prkacb), Epac1 (Rapfgef3), and Epac 2 (Rapgef4). mRNA expression normalized to 18s expression in each tissue. 


\begin{tabular}{|c|c|c|c|c|}
\hline Gene & $\begin{array}{l}\text { NCBI } \\
\text { Number }\end{array}$ & Length & Forward & Reverse \\
\hline $18 \mathrm{~s}$ & NR_003278.3 & 149bp & $\begin{array}{l}\text { 5'- } \\
\text { CGCCGCTAGAAGTGAAAT } \\
\text { TCTT-3' }\end{array}$ & $\begin{array}{l}\text { 5'- } \\
\text { CAGTCGGCATCGTTTATG } \\
\text { GTC-3' }\end{array}$ \\
\hline Adcy1 & NM_009622.1 & 115bp & $\begin{array}{l}\text { 5'- } \\
\text { TGCAGACATCGTGGGTTT } \\
\text { CA-3' }\end{array}$ & $\begin{array}{l}\text { 5'- } \\
\text { ACAGTGGTTTTCGGCTA-3 }\end{array}$ \\
\hline Adcy2 & NM_153534.2 & 140bp & $\begin{array}{l}\text { 5'- } \\
\text { CTAAACCGAGTGCTGCTG } \\
\text { GA-3' }\end{array}$ & $\begin{array}{l}\text { 5'- } \\
\text { TTGAAGTCCGGAATGGAG } \\
\text { GC-3' }\end{array}$ \\
\hline Adcy3 & NM_138305.3 & 199bp & $\begin{array}{l}\text { '- } \\
\text { TCTGGGGTCCAAGAAGAG } \\
\text { AGA-3' }\end{array}$ & $\begin{array}{l}\text { 5'- } \\
\text { GACCCGGAATTTGGGATT } \\
\text { GTC-3' }\end{array}$ \\
\hline Adcy5 & $\begin{array}{l}\text { NM_0010127 } \\
65.4\end{array}$ & 151bp & $\begin{array}{l}\text { 5'- } \\
\text { TGATCGAGGCCATCTCGT } \\
\text { TG-3' }\end{array}$ & $\begin{array}{l}\text { 5'- } \\
\text { TGGTTGGCCAGAGTGACA } \\
\text { TC-3' }\end{array}$ \\
\hline Adcy 6 & NM_007405.2 & 162bp & $\begin{array}{l}\text { 5'- } \\
\text { TGCGGTGAGGGAGAATC } \\
\text { ACT-3' }\end{array}$ & $\begin{array}{l}\text { 5'- } \\
\text { ACACCTGTTACCTCACGC } \\
\text { AC-3' }\end{array}$ \\
\hline Adcy8 & $\begin{array}{l}\text { NM_0012919 } \\
03.1\end{array}$ & 191bp & $\begin{array}{l}\text { 5'- } \\
\text { CCGCATCTACATCCATCG } \\
\text { CT-3' } \\
\end{array}$ & $\begin{array}{l}\text { 5'- } \\
\text { AGTAGTAGCAGTCCCCCA } \\
\text { GG-3' }\end{array}$ \\
\hline Prkaca & NM_008854.5 & 96bp & $\begin{array}{l}\text { '- } \\
\text { TTTGCCAAGCGTGTGAAA } \\
\text { GG-3' }\end{array}$ & $\begin{array}{l}\text { 5'- } \\
\text { AGCCTTGTTGTAGCCTTT } \\
\text { GCT-3' } \\
\end{array}$ \\
\hline Prkacb & NM_011100.4 & 122bp & $\begin{array}{l}\text { 5'- } \\
\text { TGCAGCCCAGATTGTGCT } \\
\text { AA-3' }\end{array}$ & $\begin{array}{l}\text { 5'- } \\
\text { ACCCGAAATCTGTGACCT } \\
\text { GG-3' }\end{array}$ \\
\hline $\begin{array}{l}\text { Rapgef } \\
3\end{array}$ & $\begin{array}{l}\text { NM_0011778 } \\
10.1\end{array}$ & 145bp & $\begin{array}{l}\text { '- } \\
\text { GGAAGTGCATGAGCTGAC } \\
\text { CC-3' }\end{array}$ & $\begin{array}{l}\text { 5'- } \\
\text { CACCTGGTGGATCCTGTT } \\
\text { GAAG-3' }\end{array}$ \\
\hline $\begin{array}{l}\text { Rapgef } \\
4\end{array}$ & $\begin{array}{l}\text { NM_0012041 } \\
65.1\end{array}$ & 96bp & $\begin{array}{l}\text { 5'- } \\
\text { TCCAAGAGCTGCCTCCAT } \\
\text { TG-3' }\end{array}$ & $\begin{array}{l}\text { 5'- } \\
\text { GAATCAACGTCCCTCAGA } \\
\text { AT-3' }\end{array}$ \\
\hline Gapdh & $\begin{array}{l}\text { NM_0012897 } \\
26.1\end{array}$ & 85bp & $\begin{array}{l}\text { 5'- } \\
\text { TGACCTCAACTACATGGT } \\
\text { CTACA-3' }\end{array}$ & $\begin{array}{l}\text { 5’- } \\
\text { CTTCCCATTCTCGGCCTT } \\
\text { G-3' }\end{array}$ \\
\hline
\end{tabular}

Supplemental Table 1. Gene Specific Primers Used for qRT-PCR. The NCBI gene accession number, resulting base pair length, and both the forward and reverse primers for each gene for qRT-PCR analysis. 